\title{
FORMULASI TABLET HISAP KOMBINASI EKSTRAK TEH HIJAU, PEGAGAN DAN JAHE MERAH DENGAN VARIASI KONSENTRASI NA-SIKLAMAT
}

\author{
Yulianita \\ Program Studi Farmasi, Fakultas Matematika dan Ilmu Pengetahuan Alam, \\ Universitas Pakuan \\ Email: yulianita.susilo@gmail.com
}

\begin{abstract}
ABSTRAK
Teh hijau, pegagan dan jahe merah merupakan beberapa tanaman yang memiliki khasiat baik untuk kesehatan dan salahsatu khasiatnya adalah sebagai peningkat stamina. Sehingga dilakukan penelitian formulasi kombinasi ketiga tanaman tersebut sebagai tablet hisap. Telah dilakukan formulasi tablet hisap yang mengandung bahan aktif ekstrak teh hijau, jahe merah dan pegagan dengan perbedaan kadar pemanis Na siklamat $(0.5,1$, dan 2 $\%$ ) dibuat dengan metode granulasi basah dan diuji karakteristik fisik dan uji kesukaan. Hasil uji karakteristik fisik menunjukkan bahwa tablet hisap formula I dan II telah memenuhi persyaratan Farmakope Indonesia IV, sedangkan formula III dan IV tidak memenuhi persyaratan. Hasil uji kesukaan menunjukkan bahwa tablet hisap yang lebih disukai baik dari segi aroma, warna dan rasa adalah tablet hisap formula IV.
\end{abstract}

Kata kunci: tablet hisap, ektrak teh hijau, ekstrak jahe merah dan ekstrak pegagan

\section{LOZENGES FORMULATION WITH COMBINATION OF GREEN TEA, GOTUCOLA AND RED GINGER EXTRACT WITH}

\begin{abstract}
Green tea, gotucola and red ginger is plant with a good benefit for health, and one of the benefit is for stimulant. It is done a formulation of lozenges research from green tea, gotucola and red ginger for the active compound with the diversification of sweetening agent $\mathrm{Na}$ Siklamat $(0,5 ; 1 ; 2 \%)$ made with wet granulation ant evaluate the physical and hedonic. The result of physical evaluation show that the lozenges in Formula I and Formula II is fulfill the requisite of Farmakope Indonesia IV edition, but Formula III and Formula IV has not fulfill the requisite of Farmakope Indonesia IV edition. The hedonic test show the most favourite lozenges in aroma, color and taste is lozenges Formula IV.
\end{abstract}

Key words: lozenges, green tea extract, gotucola extract, red ginger extract

\section{PENDAHULUAN}

Seiring dengan berkembangnya trend kembali ke alam "Back to nature", penggunaan obat tradisional terutama yang berasal dari tumbuh-tumbuhan atau obat herbal juga terus meningkat.Penggunaan tanaman obat tersebut dapat berupa ramuan tunggal atau ramuan campuran.Beberapa tanaman yang memiliki khasiat baik untuk pengobatan adalah teh hijau, jahe merah dan pegagan.Teh hijau (Camellia sinensis L.
Kuntze Var. Assamica) memiliki kandungan flavonoid sebagai antioksidan yang bersifat antikarsinogenik, kariostatik serta hipokolesterolemik. Beberapa peneliti lain juga menyebutkan bahwa teh mempunyai aktivitas sebagai hipoglikemik, tonikum serta dapat menghambat aterosklerosis (Tuminah, 2004).

Jahe merah (Zingiber officinale Roxb.) secara empiris biasa digunakan masyarakat sebagai obat masuk angin, gangguan 
pencernaan, analgesik, antipiretik, tonikum, anti inflamasi, dan lain-lain. Berbagai penelitian ilmiah membuktikan bahwa jahe merah mempunyai sifat antioksidan. Beberapa komponen utama dalam jahe seperti gingerol, shogaol, dan gingeron dilaporkan memiliki aktivitas antioksidan di atas vitamin E. Selain itu jahe juga mempunyai aktivitas antiemetik dan digunakan untuk mencegah mabuk perjalanan. Disebutkan pula bahwa konsumsi ekstrak jahe merah dalam minuman fungsional dan obat tradisional dapat meningkatkan ketahanan tubuh dan mengobati diare (Suhirman, 2012).

Pegagan (Centella asiatica (L) Urban) adalah salah satu dari 10 jenis tanaman terlaris di dunia yang mempunyai potensi untuk dikembangkan sebagai tanaman obat. Kandungan asiatikosida, tanin, terpen, saponin, flavonoid serta garam mineral membuat pegagan berkhasiat sebagai obat untuk memperbaiki dan merevitalisasi pembuluh darah dan sel-sel yang rusak dalam tubuh, menurunkan tekanan darah tinggi dan dapat menyembuhkan penyakit HIV melalui peningkatan daya tahan tubuh pasien (Amirudin, 2011).

Penggunaan bahan-bahan obat alam ini secara tradisional dilakukan dengan cara merebus atau menggodok. Hal ini dirasa kurang praktis untuk dilakukan setiap hari sehingga perlu dibuat sediaan farmasi yang lebih praktis dan menarik berupa tablet hisap. Tablet hisap mudah digunakan yaitu cukup dihisap dan tidak perlu menggunakan air untuk menelannya karena tablet langsung kontak dengan cairan saliva yang ada dalam mulut sehingga tablet akan pecah dengan sendirinya. Tablet hisap akan hancur secara perlahan dalam mulut sehingga kontak dengan rangsang rasa (taste) lebih lama, oleh karena itu pada formula tablet hisap tersebut komposisi bahan aktif dan bahan tambahan sedapat mungkin dipilih dan di formulasi sehingga mampu menutupi rasa tidak enak dari bahan aktifnya.

Formulasi tablet hisap dalam bentuk tunggal dari tanaman obat ini pernah dilakukan baik untuk teh hijau, jahe merah maupun pegagan. Sehingga pada penelitian ini akan dilakukan formulasi tablet hisap kombinasi dari tanaman obat tersebut, yaitu teh hijau, jahe merah dan pegagan. Kombinasi dari sediaan farmasi ini diharapkan dapat dikonsumsi oleh masyarakat untuk meningkatkan kekebalan tubuh, meningkatkan stamina dan menjaga fungsi - fungsi tubuh yang lain, sehingga dapat mendukung aktivitas sehari - hari dan mencegah timbulnya kelelahan.

\section{METODE PENELITIAN}

Penelitian ini dilakukan pada bulan Mei - September 2013 di Laboratorium Farmasi, Fakultas Matematika dan Ilmu Pengetahuan Alam, Universitas Pakuan, Bogor.

\section{Bahan}

Daun Teh hijau, herba pegagan, rimpang jahe merah yang diperoleh dari BALITTRO, Cimanggu Bogor, gom arab, Natrium Siklamat, Nipagin-Nipasol, laktosa, Mg Stearat dan Aerosil.

\section{Alat}

Mesin cetak tablet, granul flow tester, moisture balance (AND MX-50®), hardness tester (Schleuniger-2E®), friabilator (Panjaya teknik $\left.{ }^{\circledR}\right)$, disintegration tester (LIJ1®) dan alat-alat gelas lainnya.

\section{Cara Kerja \\ Pembuatan Ekstrak}

Ekstrak teh hijau, jahe merah dan herba pegagan dibuat dengan cara maserasi, yaitu dimasukkan satu bagian serbuk kering simplisia ke dalam maserator, ditambah 10 bagian pelarut (etanol 70\%). Direndam selama 6 jam pertama sambil sekali-kali diaduk, kemudian diamkan selama 18 jam. Maserat dipisahkan dengan cara pengendapan, sentrifugasi, dekantasi atau filtrasi. Proses penyarian diulangi dua kali dengan etanol $70 \%$ dengan jumlah yang sama.

Hasil maserat dikumpulkan, kemudian diuapkan dengan penguap vacuum hingga diperoleh ekstrak kental. 


\begin{abstract}
Rendemen dihitung dengan mempresentasekan bobot (b/b) antara rendemen dengan bobot serbuk simplisia yang digunakan.
\end{abstract}

\section{Pembuatan Sediaan Tablet Hisap}

\section{a. Formulasi Tablet Hisap}

Tablet hisap dibuat dengan metode granulasi basah. Gom arab dibuat dengan pelarut yang berbeda yaitu dengan aquadest dan orange water selain itu, pemanis digunakan dengan konsentrasi yang berbeda untuk mendapatkan tablet hisap yang daya terima rasa yang baik. Ekstrak yang digunakan adalah ekstrak teh hijau, jahe merah dan pegagan.

Tabel 1. Formulasi Tablet Hisap

\begin{tabular}{|c|c|c|c|c|c|}
\hline \multirow{2}{*}{ Nama Bahan } & \multicolumn{4}{|c|}{ Formulasi (\%) } & \multirow{2}{*}{$\begin{array}{l}\text { Jenis } \\
\text { Fase }\end{array}$} \\
\hline & I & II & III & IV & \\
\hline $\begin{array}{l}\text { Ekstrak } \\
\text { Teh Hijau }\end{array}$ & $200 \mathrm{mg}$ & $200 \mathrm{mg}$ & $200 \mathrm{mg}$ & $200 \mathrm{mg}$ & \\
\hline $\begin{array}{l}\text { Ekstrak } \\
\text { Jahe Merah }\end{array}$ & $50 \mathrm{mg}$ & $50 \mathrm{mg}$ & $50 \mathrm{mg}$ & $50 \mathrm{mg}$ & \\
\hline $\begin{array}{l}\text { Ekstrak } \\
\text { Pegagan }\end{array}$ & $50 \mathrm{mg}$ & $50 \mathrm{mg}$ & $50 \mathrm{mg}$ & $50 \mathrm{mg}$ & \\
\hline Gom Arab & $\begin{array}{c}6,0 \\
\text { Dilarutkan } \\
\text { dengan } \\
\text { aquadest }\end{array}$ & $\begin{array}{c}6,0 \\
\text { Dilarutkan } \\
\text { dengan } \\
\text { orange } \\
\text { water }\end{array}$ & $\begin{array}{c}6,0 \\
\text { Dilarutkan } \\
\text { dengan } \\
\text { orange } \\
\text { water }\end{array}$ & $\begin{array}{c}6,0 \\
\text { Dilarutkan } \\
\text { dengan } \\
\text { orange } \\
\text { water }\end{array}$ & $\begin{array}{c}\text { Fase } \\
\text { Dalam } \\
(\mathrm{FD})\end{array}$ \\
\hline Na Siklamat & 0,5 & 0,5 & 1,0 & 2,0 & \\
\hline $\begin{array}{l}\text { Nipagin:Nipasol } \\
(2: 1)\end{array}$ & 0,075 & 0,075 & 0,075 & 0,075 & \\
\hline Laktosa & qs & qs & qs & qs & \\
\hline Mg stearat & 1 & 1 & 1 & 1 & $\begin{array}{l}\text { Fase } \\
\text { Luar }\end{array}$ \\
\hline Aerosil & 0,5 & 0,5 & 0,5 & 0,5 & (FL) \\
\hline
\end{tabular}

Granul yang telah terbentuk kemudian dievaluasi meliputi; penetapan kandungan lembab, sifat alir, kompresibilitas dan distribusi ukuran partikel. Setelah memenuhi persyaratan, granul kemudian dicetak. Tablet hasil cetak kemudian dievaluasi meliputi; uji penampilan, keseragaman ukuran, keseragaman bobot, kekerasan, kerenyahan dan waktu hancur serta uji kesukaan/ hedonik.

\section{HASIL DAN PEMBAHASAN Hasil Perolehan Ekstrak}

Pembuatan ekstrak teh hijau, jahe merah dan pegagan dilakukan dengan metode maserasi.Pemerian untuk ekstrak teh hijau berupa ekstrak kental, warna hijau tua, berbau khas lemah dan rasa agak pahit. Pemerian ekstrak jahe merah berupa ekstrak kental, warna kuning kecoklatan, berbau khas jahe dan rasa pedas. Pemerian ekstrak pegagan berupa ekstrak kental, warna coklat tua, berbau tidak khas dan rasa agak pahit. Ekstrak kental selanjutnya dikeringkan dengan menggunakan alat Spray dry sehingga dihasilkan ekstrak kering. Ekstrak yang diperoleh kemudian ditimbang dah dihitung rendemennya. Rendemen masingmasing ekstrak disajikan pada Tabel 2. 
Tabel 2. Hasil Perolehan Ekstrak

\begin{tabular}{lccc}
\hline \multicolumn{1}{c}{ Jenis Ekstrak } & Rendemen (\%) & Syarat (\%) & Keterangan \\
\hline Ekstrak Teh Hijau & 37,78 & $>32$ & Memenuhi syarat \\
Ekstrak Jahe Merah & 12,96 & $>6,6$ & Memenuhi syarat \\
Ekstrak Pegagan & 15,21 & $>7,2$ & Memenuhi syarat \\
\hline
\end{tabular}

Data di atas menunjukkan bahwa ekstrak yang dihasilkan telah memenuhi persyaratan, hal ini berarti proses ekstraksi dan pelarut yang digunakan sesuai untuk masing-masing tanaman yang diekstraksi sehingga zat aktif dapat tertarik secara maksimal.

Tabel 3. Hasil Penentuan Kadar Air Granul

\begin{tabular}{lcccc}
\hline \multicolumn{1}{c}{ Granul } & Kadar air (\%) & Granul & Kadar air (\%) \\
\hline Formula I & 3,44 & Formula III & 3,07 \\
Formula II & 3,09 & Formula IV & 3,23 \\
\hline
\end{tabular}

\section{Hasil Evaluasi Granul}

\section{Penetapan Kandungan Lembab}

Penetapan kandungan lembab atau kadar air dilakukan karena sangat berpengaruh terhadap pembuatan tablet. Kadar air yang terlalu rendah dapat membuat tablet rapuh sedangkan apabila kadar air terlalu tinggi akan mengakibatkan tablet lembab. Selain itu, kadar air mempengaruhi kecepatan alir dari granul, apabila kadar air terlalu rendah maka kecepatan alir akan tinggi sehingga baik pada saat pengempaan sedangkan apabila kadar air terlalu tinggi maka kecepatan alir menjadi rendah dan menyulitkan pada saat pencetakan. Hasil penentuan kadar air granul tablet hisap disajikan pada Tabel 3.
Syarat kadar air untuk granul yang siap dicetak adalah $3-5 \%$. Hal ini berarti bahwa kadar air granul pada setiap formula tablet hisap telah memenuhi persyaratan kadar air dan siap untuk dicetak.

\section{Penetapan Sifat Alir dan Sudut Baring}

Penetapan sifat alir dan sudut baring pada granul ditujukan agar granul dapat mengalir dengan baik dari hopper pada saat pencetakan tablet sehingga tablet dapat memiliki keseragaman bobot yang baik. Hasil penetapan sifat alir dan sudut baring ditunjukkan pada Tabel 4 dan 5 .

Tabel 4. Hasil Penetapan Sifat Alir (detik)

\begin{tabular}{ccccc}
\hline Pengulangan & Formula I & Formula II & Formula III & Formula IV \\
\hline \multicolumn{1}{c}{1} & 10,5 & 5,51 & 6,16 & 6,15 \\
2 & 10,7 & 5,67 & 6,12 & 5,89 \\
\multicolumn{1}{c}{ c } & 9,8 & 5,33 & 6,15 & 5,78 \\
\hline Rata-rata & 10,33 & 5,50 & 6,14 & 5,94 \\
SD & 0,386 & 0,139 & 0,017 & 0,155 \\
\hline
\end{tabular}

Tabel 5. Hasil Penetapan Sudut Baring $\left(^{\circ}\right)$

\begin{tabular}{ccccc}
\hline Parameter & Formula I & Formula II & Formula III & Formula IV \\
\hline $\mathrm{h}(\mathrm{cm})$ & 2,4 & 2,4 & 2,6 & 2,5 \\
$\mathrm{r}(\mathrm{cm})$ & 8,3 & 8,7 & 8,5 & 8,5 \\
$\operatorname{tg} \alpha$ & 0,289 & 0,276 & 0,306 & 0,294 \\
$\mathrm{~A}$ & 16,12 & 15,43 & 17,01 & 16,38 \\
\hline
\end{tabular}

Keterangan: $\mathrm{h}=$ tinggi

$$
\mathrm{r}=\text { diameter }
$$


Data di atas menunjukkan bahwa granul telah memenuhi persyaratan untuk sifat alir dan sudut baring. Rata-rata sudut baring granul adalah 16,23 . Berdasarkan tabel hubungan sudut baring dan sifat alir, nilai sudut baring $<25^{\circ}$ memiliki arti bahwa granul memiliki sifat aliran yang sangat baik.

\section{Penetapan Sifat Kemampatan atau Kompresibilitas}

Sifat kemampatan atau kompresibilitas diuji untuk dapat mengetahui sifat aliran granul. Hasil pengujian ditunjukkan pada Tabel 6.

Tabel 6. Hasil Penetapan Kompresibilitas (\%)

\begin{tabular}{ccccc}
\hline Parameter & Formula I & Formula II & Formula III & Formula IV \\
\hline $\mathrm{D}_{0}$ & 0,472 & 0,555 & 0,555 & 0,555 \\
$\mathrm{D}_{\mathrm{f}}$ & 0,568 & 0,609 & 0,641 & 0,641 \\
$\% \mathrm{I}$ & 16,9 & 9,9 & 8,6 & 8,6 \\
\hline
\end{tabular}

$\mathrm{D}_{0}=$ kompresibilitas awal $\mathrm{D}_{\mathrm{f}}=$ kompresibilitas akhir \% $\mathrm{I}=$ persen kompresibilitas

Berdasarkan tabel hubungan kompresibilitas dengan sifat aliran, Formula I dengan kompresibilitas $16,9 \%$ memiliki sifat aliran yang cukup baik sedangkan Formula II, Formula III dan Formula IV dengan nilai rata-rata kompresibilitas 9,03 memiliki sifat aliran yang sangat baik.

\section{Penetapan Distribusi Ukuran Partikel Granul \\ Distribusi ukuran partikel diuji dengan metode ayakan (sieving), hasil pengujian ditunjukkan pada Tabel 7.}

Tabel 7. Hasil Penetapan Distribusi Ukuran Partikel (\%)

\begin{tabular}{ccccc}
\hline \multirow{2}{*}{ Ukuran ayakan (mesh) } & \multicolumn{4}{c}{ Jumlah Granul (\%) } \\
\cline { 2 - 5 } & Formula I & Formula II & Formula III & Formula IV \\
\hline 16 & 0 & 0 & 0 & 0 \\
30 & 54,48 & 63,36 & 58,40 & 52,56 \\
60 & 22,44 & 14,64 & 22,48 & 26,44 \\
80 & 11,56 & 8,40 & 9,64 & 10,68 \\
100 & 3,12 & 2,36 & 2,52 & 2,08 \\
\hline Komponen serbuk & 8,4 & 8,24 & 6,96 & 8,24 \\
\hline
\end{tabular}

Granul tablet hisap yang telah diuji telah memenuhi persyaratan karena memiliki distribusi ukuran partikel yang sempit dan memiliki komponen berbentuk serbuk tidak lebih dari $10 \%$. Komponen serbuk tidak boleh lebih dari $10 \%$ karena komponen serbuk akan mengurangi jumlah tablet hisap yang dapat tercetak, selain itu banyaknya komponen serbuk akan mengakibatkan banyaknya debu pada saat proses pencetakan yang mengganggu proses pencetakan tersebut.

\section{Hasil Akhir Granul}

Granul yang telah memenuhi seluruh persyaratan ditimbang untuk mengetahui hasil akhir granul Granul akhir sebaiknya tidak terlalu banyak menyimpang dari granul yang seharusnya diperoleh, karena hasil akhir yang mendekati granul sebenarnya menyatakan bahwa proses granulasi terjadi secara maksimal dan efisien sehingga tidak banyak bahan yang tertinggal pada saat proses khususnya proses pengayakan. 
Tabel 8. Hasil Akhir Granul

\begin{tabular}{cccc}
\hline \multicolumn{3}{c}{ Granul sebenarnya } & \multicolumn{2}{c}{$250 \mathrm{~g}$} \\
\hline \multicolumn{3}{c}{ Hasil Granulasi } \\
\hline Formula I & $195,92 \mathrm{~g}$ & Formula III & $222,22 \mathrm{~g}$ \\
Formula II & $211,15 \mathrm{~g}$ & Formula IV & $220,45 \mathrm{~g}$ \\
\hline
\end{tabular}

\section{A. Hasil Evaluasi Fisik Tablet Hisap}

\section{Pemerian Tablet Hisap}

Secara garis besar, pemerian dari

tablet hisap seluruh formula menunjukkan warna hijau berbau dominan jahe merah, berbentuk bulat pipih dengan cetakan atas dan bawah rata.

\section{Keseragaman Ukuran}

Diameter tablet tidak boleh lebih dari 3 kali ketebalan tablet dan tidak kurang dari 1 1/3 kali tebal tablet. Data pengamatan menunjukkan bahwa ukuran tablet telah relatif seragam danmemenuhi persyaratan dengan rata-rata ketebalan $0,55 \mathrm{~cm}$ dan diameter $1,01 \mathrm{~cm}$.

\section{Keseragaman Bobot}

Keseragaman bobot erat kaitannya dengan keseragaman kandungan, karena dengan bobot yang relatif seragam maka kandungan zat aktif akan relatif seragam pula. Hasil evaluasi menunjukkan bahwa bobot rata-rata dari tablet Formula I, II, III dan IV secara berturut-turut adalah (544,5 \pm $11,46) ;(550,5 \pm 17,91) ;(530,5 \pm 9,99)$ dan $(507 \pm 7,33)$. Persyaratan keseragaman bobot untuk tablet adalah jika ditimbang satu persatu, tidak boleh lebih dari 2 tablet yang masing-masing bobotnya menyimpang dari bobot rata-rata lebih besar dari harga yang di tetapkan kolom A (range $\pm 5 \%$ ), dan tidak 1 tablet pun yang menyimpang dari bobot ratarata pada kolom B (range $\pm 10 \%$ ). Berdasarkan hasil pengamatan di atas, dapat dilihat dan disimpulkan bahwa baik untuk tablet hisap Formula I, Formula II, Formula III dan Formula IV telah memenuhi persyaratan dari keseragaman bobot. Hal ini berarti bahwa bahan tambahan berupa $\mathrm{Mg}$ Stearat dan Aerosil telah memiliki fungsi yang maksimal sehingga granul dapat mengalir dari hopper dan tercetak dengan baik.

\section{Kekerasan}

Tablet hisap disyaratkan memiliki kekerasan yang lebih tinggi dari tablet biasa yaitu antara $10-20 \mathrm{kp} / \mathrm{cm}$. Kekerasan yang lebih tinggi bertujuan agar tablet terkikis perlahan dalam mulut. Hasil pengujian kekerasan menunjukkan bahwa tablet hisap Formula I dan Formula II memiliki kekerasan yang memenuhi syarat untuk tablet hisap yaitu kekerasannya antara 10 $20 \mathrm{kp} / \mathrm{cm}$. Tetapi tablet hisap Formula III dan Formula IV memiliki kekerasan yang tidak memenuhi persyaratan karena kekerasan rata-rata hanya $6,06 \mathrm{kp} / \mathrm{cm}$. Penyebab perbedaan kekerasan pada keempat formula terdapat pada penyetelan kekerasan pada mesin cetak tablet, bukan pada penambahan pengikat karena pengikat yang digunakan pada masing-masing formula berjumlah sama yaitu 20\%. Mesin cetak tablet yang digunakan memiliki kekurangan pada saat pengoprasiannya karena harus disetel secara manual untuk menentukan berat tablet, ukuran dan kekerasan tablet.

Untuk mendapatkan kekerasan yang sesuai, tindakan yang dapat dilakukan pada tablet hisap formula III dan IV adalah slugging.Tablet dipecah kembali menjadi granul, lalu dilakukan pencetakan tablet ulang sampai diperoleh kekerasan yang sesuai dan memenuhi persyaratan untuk tablet hisap.

\section{Kerenyahan/ Friabilita}

Persen friabilita ditentukan untuk mengetahui ketahanan tablet terhadap goncangan atau gangguan mekanik pada saat pengemasan, distribusi sampai ditangan konsumen. Friabilita yang baik untuk tablet adalah kurang dari $1 \%$. Hasil pengujian friabilita untuk tablet Formula I 0,247\%, Formula II $0,160 \%$, Formula III $0,343 \%$ dan 
Formula IV $0,165 \%$. Sehingga dapat disimpulkan tablet telah memenuhi persyaratan friabilita.

\section{Waktu Hancur}

Pengujian waktu hancur dimaksudkan untuk dapat mengetahui perkiraan obat untuk dapat hancur di dalam tubuh. Pengujian dilakukan secara in vitro dengan menggunakan alat uji waktu hancur (Disintegration tester) pada suhu yang sama dengan suhu tubuh normal yaitu $37^{\circ} \mathrm{C}$.

Waktu hancur yang baik untuk tabet hisap adalah kurang dari 30 menit. Rata-rata waktu hancur untuk tablet hisap Formula I 26 menit, Formula II 18 menit, Formula III 17 menit dan Formula IV 19 menit.Data pengujian menunjukkan bahwa waktu hancur untuk keempat formula tablet hisap yang dibuat telah memenuhi persyaratan yaitu kurang dari 30 menit, hal ini berarti penambahan bahan pengikat telah sesuai dalam formulasi tablet hisap. Adapun perbedaan waktu hancur untuk masingmasing formula terletak dari proses pengempaan tablet hisap, hal ini didukung dari hasil pengamatan kekerasan yang menyatakan bahwa kekerasan tablet hisap Formula I dan II lebih besar dibandingkan dengan kekerasan tablet hisap Formula III dan Formula IV.

Memperhatikan rangkuman keseluruhan evaluasi tablet hisap, dapat disimpulkan bahwa ditinjau dari segi fisik keempat formula tablet hisap dapat memenuhi persyaratan tablet hisap, dengan catatan untuk tablet hisap Formula III dan Formula IV dilakukan slugging dan pengempaan ulang. Pemilihan formula terbaik ditinjau dari kriteria tablet yang lain berupa uji kesukaan.

\section{B. Hasil Uji Kesukaan/ Hedonik}

Uji kesukaan dilakukan terhadap 20 orang panelis.Panelis yang terlibat memiliki kriteria pria atau wanita sehat dengan umur antara 18 sampai dengan 25 tahun. Parameter pengujian hedonik tablet hisap berupa penilaian dari segi aroma, warna, rasa dan penilaian secara keseluruhan. Penilaian tingkat kesukaan didasarkan dengan skala numerik, yaitu: 5 (sangat suka), 4 (suka), 3 (netral/ agak suka), 2 (tidak suka) dan 1 (sangat tidak suka).

Hasil uji kesukaan kemudian dianalisis dengan statistik menggunakan program SPSS. Pengujian statistik untuk parameter aroma menunjukkan bahwa terdapat perbedaan yang nyata dari segi aroma pada masing-masing formula, namun setelah dilakukan uji lanjut dengan uji Duncan diketahui bahwa formula III, II dan IV tidak memiliki perbedaan yang nyata, sedangkan Formula I dan IV berbeda nyata dengan formula II dan III. Pengujian statistik untuk parameter warna menunjukkan bahwa terdapat perbedaan yang nyata dari segi warna pada masing-masing formula, namun setelah dilakukan uji lanjut dengan uji Duncan diketahui bahwa formula III berbeda nyata dengan Formula IV dan I, formula II tidak berbeda dengan formula IV, dan formula I berbeda nyata dengan formula II, III dan IV. Pengujian statistik untuk parameter rasa menunjukkan bahwa terdapat perbedaan yang nyata dari segi rasa pada masing-masing formula, namun setelah dilakukan uji lanjut dengan uji Duncan diketahui bahwa tidak terdapat perbedaan yang nyata untuk Formula I, II dan III, sedangkan Formula IV berbeda nyata terhadap Formula I, II dan III.

Pengujian statistik untuk parameter secara keseluruhan menunjukkan bahwa terdapat perbedaan yang nyata pada masingmasing formula, namun setelah dilakukan uji lanjut dengan uji Duncan diketahui bahwa tidak terdapat perbedaan yang nyata untuk Formula I, II dan III, sedangkan Formula IV berbeda nyata terhadap Formula I, II dan III.Berdasarkan hasil ini, dapat diketahui bahwa tablet hisap yang lebih diterima oleh panelis adalah tablet hisap Formula IV.

Panelis juga menambahkan saran dalam setiap kuisioner yang diisi.Saran yang dituliskan mengenai aroma, warna dan rasa dari tablet hisap. Pada segi aroma, panelis menyatakan bahwa aromanya menarik, tercium jelas sebagai aroma khas dari jahe, pada segi warna, panelis menyatakan bahwa 
warna dari tablet hisap kurang menarik, karena tampak jelas seperti warna jamu, sedangkan pada segi rasa para penelis menyatakan bahwa tablet hisap masih terasa pahit dan perlu adanya penambahan atau pemilihan pemanis lain yang lebih sesuai.

\section{SIMPULAN DAN SARAN}

\section{A. SIMPULAN}

1. Empat formula tablet hisap kombinasi ekstrak teh hijau, jahe merah dan pegagan dapat dibuat dengan hasil yang memenuhi persyaratan

2. Berdasarkan uji hedonik tablet hisap yang paling disukai adalah tablet hisap formula IV karena secara keseluruhan memiliki rasa yang lebih baik dari formula I, II dan III, namun rasa pahit masih terasa setelah dikonsumsi. Sedangkan untuk parameter aroma dan warna, tidak ada perbedaan dari masingmasing formula.

\section{B. SARAN}

Disarankan agar tablet hisap diformulasi kembali sehingga memperoleh rasa, aroma dan warna yang lebih menarik lagi, dan disarankan agar dilakukan pengujian stabilitas untuk menentukan masa simpan produk.

\section{DAFTAR PUSTAKA}

Amirudin A. 2011. Formulasi Granul Instan Ekstrak Herba Pegagan (Centella asiatica (L) Urban) Bogor: Universitas Pakuan.

Ansel, H.C. 2005. Pengantar Bentuk Sediaan Farmasi. Edisi keempat. Jakarta: UIPress.

Azizahwati.2003. Uji Khasiat dan Keamanan Obat Herbal. Dalam: Simposium "Obat Herbal dan Akupuntur Estetika pada Era 2003". Perhimpunan Kedokteran Komplementer dan Alternatif

Indonesia (PKKAI) dengan Pusat Studi Obat Bahan Alam Jurusan Farmasi (FMIPA - UI) dan Badan POM. Jakarta.
Lachman L., Lieberman A.H., Kanig L.J. 1994. Teori dan Praktek Farmasi Industri II.Edisi ketiga.Diterjemahkan oleh Siti Suyatmi. Jakarta: UI - Press.

Mun'im A., Hanani E. 2011. Fitoterapi Dasar. Jakarta: Dian Rakyat.

Siregar C.J.P., Wikarsa S. 2010. Teknologi Farmasi Sediaan Tablet, Dasar-dasar Praktis. Jakarta: Penerbit Buku Kedokteran EGC.

Suhirman S, Winarti C. Prospek dan Fungsi Tanaman Obat Sebagai Immunomodullator. Diambil dari: http://balittro.litbang.deptan.go.id/ind/in dex.php?option=com_content $\&$ view $=$ article\&id $=254$. Diakses 15 Februari, 2012.

Tuminah S. 2004. Teh (Camellia sinensis L. Kuntze Var. Assamica) Sebagai Salah Satu Sumber Antioksidan. Cermin Dunia Kedokteran; No.144: 52-54. 